\title{
Inflammatory Versus Degenerative (Non Inflammatory) Ultrasound Detected Shoulder Abnormalities in Rheumatoid Arthritis Patients with Shoulder Pain
}

\author{
MERVAT ABO GABAL, M.D. and SHERIN HOSNY, M.D. \\ The Department of Internal Medicine and Rheumatology, Ain Shams University Hospital, Cairo, Egypt
}

\begin{abstract}
Background: The early and definitive diagnosis of a chronic inflammatory joint disease in Rheumatoid Arthritis (RA) is crucial for initiating optimal treatment. Conventional radiography detects late changes such as joint destruction, but fails to visualize inflammation in synovial membrane.
\end{abstract}

Aim of Study: To compare type and frequency of Ultrasound (US) abnormal findings (inflammatory versus degenerative (non inflammatory)) detected in shoulders of RA patients with shoulder pain in relation to disease characteristics.

Patients and Methods: Musculoskeletal US (MSUS) shoulder examination and plain radiography were performed bilaterally for 45 RA patients and 45 controls with only painful shoulder and compared.

Results: Comparison between RA patients and controls in number (No) and frequency of inflammatory shoulder findings detected by MSUS (active bursitis, synovitis, tenosynovitis, erosions) revealed statistical significant difference (43 (47.8\%) versus $18(20.0 \%)$, respectively), $p=0.000$. There was no statistical significant difference between RA patients and controls in No. and frequency of non-inflammatory findings detected by MSUS (chronic bursitis, tendinopathy, tendon tears, osteophytes), (65 (72.2\%) versus 60 (66.7\%), respectively), $p=0.418$. In RA patients, inflammatory MSUS findings were significantly related to shoulder pain, older ages and higher $\operatorname{ESR} p<0.05$. MSUS detected erosions in 42 (180) shoulders versus 6 (180) by X-ray, of the 42 MSUS detected erosions, X-ray detected only $4(9.5 \%)$. Of the 138 MSUS-ve erosions, X-ray agreed in $136(98.6 \%)$, kappa $=0.115$, $p=0.01$.

Conclusion: MSUS detected shoulder inflammatory abnormalities are more frequent, symptomatic, usually bilateral in RA patients. They are related to shoulder pain, old age and disease activity. Early diagnosis of joint lesions by MSUS, proved superiority to conventional radiography, is crucial for initiating optimal treatment.

Key Words: Ultrasound shoulder - Rheumatoid arthritis Inflammatory lesions - Pain.

Correspondence to: Dr. Mervat Abo Gabal, The Department of Internal Medicine and Rheumatology, Ain Shams University Hospital, Cairo, Egypt

\section{Introduction}

SHOULDER involvement is frequent during the natural history of Rheumatoid Arthritis (RA). Several structures can be targeted by the disease; especially the glenohumeral joint (GH) [1] . In addition to the synovitis of the glenohumeral joint, shoulder pain in RA arises from pathologies involving diverse periarticular soft tissues and the involvement of more than one anatomical structure is common [2].

Only a small proportion of patients has clinically detectable shoulder tenderness and swelling, whereas up to $5 \%$ of patients after 2 years and $96 \%$ after 12 years show erosive damage at the shoulder $[3,4]$. Thus, clinical evaluation of shoulder does not offer an accurate assessment of this joint [5]. Moreover, conventional radiography ascertains tardily the diagnosis. Owing to the necessity of early treatment in RA patients before the damage occurrence [6], ultrasound and Magnetic Resonance (MR) imaging have already been compared with conventional radiography for the assessment of the peripheral joints of RA patients in several studies, and both have been found to have a higher sensitivity than radiography in detecting erosions [7-10].

Little attention has so far been paid to the proximal joints of the arms, although the shoulder joints tend to show abnormal changes in a high percentage of patients when RA first becomes manifest. Clinical symptoms, such as pain and restriction of movement, may not occur before the destructive changes of the joints can be demonstrated [11].

Musculoskeletal Ultrasonography (MSUS) has a great role in detecting subclinical abnormalities 
in rheumatoid shoulder in order to achieve a low disease status and eventually remission [12]. In comparison with the various modalities currently available for diagnosing rotator cuff disorders, ultrasonography has a series of advantages, including the following: It is more widely available and far more cost-effective; it allows dynamic examination of the structures; comparison can be easily made between the affected shoulder and the contralateral side; and finally, it provides immediate feedback for the patient/clinician [1].

The aim of the present study was to compare types and frequency of MSUS detected shoulder inflammatory versus degenerative (non-inflammatory) abnormalities in RA patients with shoulder pain in relation to disease characteristics.

\section{Patients and Methods}

This cross sectional case control study was performed on 45 consecutive RA patients with unilateral or bilateral shoulder pain visiting Ain Shams University Rheumatology Clinic diagnosed according to ACR/EULAR 2010 criteria [13] in the period between January 2017 and January 2018. In addition 45 age and sex matched patients with only unilateral or bilateral shoulder pain were enrolled serving as controls. Patients with other rheumatologic disorders (SLE, Spondyloarthropathy) or evidence of endocrine or traumatic diseases affecting shoulder were excluded from the study. Oral consents were obtained from all participants after explaining the nature of the study. The study was approved by the Local Research Ethical Committee of Ain Shams University and conforms to the provisions of the Declaration of Helsinki in 1995.

For all patients, detailed history taking and thorough clinical and musculoskeletal examination were performed. Calculation of BMI=weight/ height ${ }^{2}$. Measurement of Erythrocyte Sedimentation Rate (ESR), C-Reactive Protein (CRP) was performed. Serum Rheumatoid Factor (RF) and anti$\mathrm{CCP}$ antibodies positivity and levels were done by ELISA. Rheumatoid arthritis activity was assessed using DAS 28-ESR score [14]. Plain X-ray shoulder region (postero-anterior view) was performed bilaterally. High resolution Musculoskeletal Ultrasonography (MSUS) examination (by gray scale and power Doppler both in longitudinal and transverse planes) was performed by a single experienced operator (senior rheumatologist) by using a 6-18-MHz linear-array transducer and E-Zaote MyLab six machine, according to the technical guidelines of systematic and standardized protocol [15]. The following structures were examined: Rotator cuff tendons (T) (supraspinatus (supra-sp), infraspinatus (infra-sp)/teres minor, and subscapularis (subscap.), long head of the biceps tendons, Subacromial and Subdeltoid Bursa (SASD B), Glenohumeral (GHJ) and Acromioclavicular Joints (ACJ). Tendon lesions (Tenosynovitis (TS), Subluxation (SL), Tendinopathy (TP) and full (T-tear F) or partial tear (T-tear P), tendon calcifications (calc.), bursitis (B), impingement (imp.) and all other morphological and degenerative abnormalities such as arthritic alterations of the Glenohumeral (GHJ) and Acromioclavicular Joints (ACJ) were registered $[\mathbf{1 6 , 1 7 ]}$. In all patients, images of the shoulder were obtained bilaterally for comparison and correlations.

\section{Statistical analysis:}

Data were collected, tabulated and statistically analyzed using SPSS program (Statistical Package for Social Sciences) software Version 18. Quantitative variables were described as mean, Standard Deviation (SD), median and range. Qualitative variables were described as number (No.) and percentage (\%). Chi-square, Fisher's Exact, MannWhitney, independent $t$-tests were used for comparison. Kappa agreement measure was used. $p$ value was considered significant if $\leq 0.05$.

\section{Results}

This cross sectional study included 90 subjects with shoulder pain divided into 2 groups; patients group included 45 rheumatoid arthritis patients they were $39(86.7 \%)$ females and 6 males $(13.3 \%)$, their mean age was $43 \pm 11.86$ years. Their mean disease duration was $3.8 \pm 1.99$ years. Their median shoulder pain duration was 4 (1-12) months. Eighteen $(40 \%)$ of RA patients had moderate disease activity by DAS-28 ESR score and $27(60 \%)$ had severe activity. Forty five (100\%) of patients were on DMARDs, $30(66.3 \%)$ on corticosteroids and $25(55.5 \%)$ on NSAIDs. Control group included 45 patients who had shoulder pain only; they were 34 females (75.6\%) and 11 male $(24.4 \%)$ with a mean age of $38.89 \pm 12.18$ years. Their median pain duration was 6 (2-11) months. Comparison between both groups as regards age, sex, BMI, shoulder pain characteristics, NO. and frequency of inflammatory and non inflammatory abnormalities detected in shoulders by MSUS are presented in (Table 1).

Comparison between RA patients and controls as regards the presence of painful shoulders (64 
(71\%) Vs. $51(56.7 \%)$ respectively) and bilateralism of pain $(19(42 \%)$ Vs. 6 (13.3\%) respectively) revealed statistical significant difference, $\chi^{2}=4.07$, $p=0.044$ and $\chi^{2}=9.36, p=0.002$ respectively.

Regarding MSUS abnormalities, 43/45 (95.5\%) RA patients had shoulder MSUS abnormalities, unilateral in $13(28.9 \%)$ and bilateral in $30(66.7 \%)$. On the other hand 41/45 (91.1\%) of the controls had MSUS shoulder abnormality, unilateral in 16 (35.6\%) and bilateral in $25(55.6 \%)$ with no statistical significant difference, $\chi=1.432, p=0.489$.

Comparison between RA patients and controls as regards the number and frequency of total inflammatory (active bursitis, synovitis, tenosynovitis, erosions) MSUS shoulder findings (43/47.8\% versus $18 / 20 \%$, respectively) revealed statistical significant difference, $p=0.0001$. On the other hand there was no statistical significant difference between both groups regarding the number (No.) and frequency $(65 / 72.2 \%$ versus $60(66.7 \%))$ of total non-inflammatory (chronic bursitis, tendinopathy, tendon tears, osteophytes) MSUS shoulder findings, $p=0.418$, Table $(1)$.

Comparison between RA patients and controls regarding the number (No.) and \% (frequency) of each shoulder MSUS abnormalities revealed statistical significant higher values in chronic SASD $\mathrm{B}$, subcoracoid $\mathrm{B}$, subcoracoid impingement, humeral head erosions, ACJ synovitis and ACJ erosions in RA patients compared to controls ( $p=0.007$, $0.047,0.023,0.0001,0.0010 .0001$ respectively), but lower in supraspinatus tendon calcification $p=$ 0.034 (Table 2).

Table (1): Comparison between RA patients and controls with shoulder pain as regards demographic and clinical characteristics and inflammatory \& non- inflammatory MSUS lesions.

\begin{tabular}{|c|c|c|c|c|}
\hline & $\begin{array}{l}\text { RA patients } \\
\text { (45) }\end{array}$ & $\begin{array}{c}\text { Controls with } \\
\text { shoulder pain (45) }\end{array}$ & $\chi^{2} / t / Z$ & $p$ \\
\hline Age (yrs) & $43 \pm 11.86$ & $38.89 \pm 12.1$ & 1.631 & 0.106 \\
\hline \multicolumn{5}{|l|}{ Sex: } \\
\hline Females & $39(86.7 \%)$ & $34(75.6 \%)$ & 0.178 & 1.813 \\
\hline Males & $6 \quad(13.3 \%)$ & $11(24.4 \%)$ & & \\
\hline BMI kg/m² & $28 \pm 5.06$ & $27.7 \pm 5.59$ & 0.253 & 0.801 \\
\hline Shoulder pain + (90 shoulders) & $64(71 \%)$ & $51(56.7 \%)$ & 4.070 & 0.044 \\
\hline Shoulder pain duration (month) & $4 \quad(1-12)$ & $6 \quad(2-11)$ & $-1.500-$ & 0.133 \\
\hline bilateralism of shoulder pain & $19(42 \%)$ & $6 \quad(13.3 \%)$ & 9.36 & 0.002 \\
\hline \multicolumn{5}{|l|}{ MSUS abnormalities } \\
\hline \multicolumn{5}{|l|}{ Inflammatory US shoulder lesions: } \\
\hline+ & $43(47.8 \%)$ & $18(20 \%)$ & 15.498 & 0.000 \\
\hline- & $47(52.2 \%)$ & $72(80 \%)$ & & \\
\hline \multicolumn{5}{|c|}{ Non inflammatory US shoulder lesions: } \\
\hline+ & $65(72.2 \%)$ & $60(66.7 \%)$ & 0.655 & 0.418 \\
\hline- & $25(27.8 \%)$ & $30(33.3 \%)$ & & \\
\hline
\end{tabular}

Inflammatory findings: (Active bursitis, synovitis, tenosynovitis, erosions).

Non-inflammatory findings: (Chronic bursitis, tendinopathy, tendon tears, osteophytes).

There were +ve (presence) inflammatory shoulder abnormalities detected by MSUS in 43/90 RA patient shoulders versus 47/90 shoulders with -ve (absence) inflammatory lesions. On the other hand non inflammatory MSUS findings were +ve in $65 / 90$ RA patient shoulders versus $25 / 90$ shoulders with -ve (absence) non inflammatory lesions. Studying the relation between inflammatory and non-inflammatory MSUS shoulder abnormalities in RA patients and different demographic and disease parameters revealed that, inflammatory MSUS findings were significantly more prevalent in older age $(p=0.006)$ and with higher $\operatorname{ESR}(p=$ 0.012 ), while non-inflammatory lesions were significantly more frequent in older ages $(p=0.01)$ (Table 3). 
Table (2): Display and comparison of individual shoulder MSUS abnormalities in RA patients (90 shoulders) and controls with shoulder pain (90 shoulders).

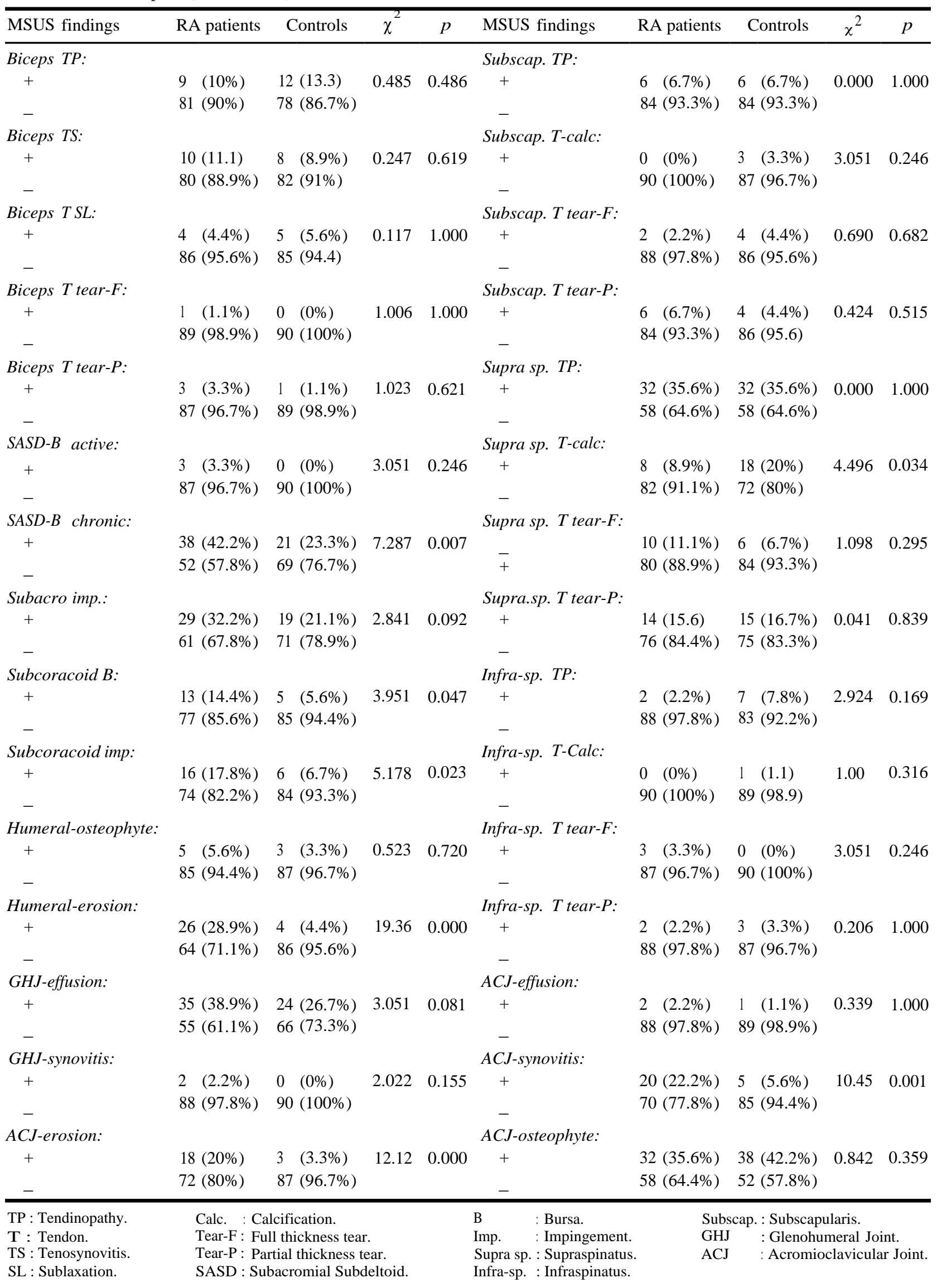


Table (3): Relation between inflammatory and non-inflammatory MSUS shoulder abnormalities in RA patients and different demographic and disease parameters.

\begin{tabular}{|c|c|c|c|c|c|c|c|c|}
\hline \multicolumn{9}{|c|}{ RA patients } \\
\hline \multirow{2}{*}{ Parameter } & \multicolumn{2}{|c|}{$\begin{array}{l}\text { Inflammatory MSUS } \\
\text { findings ( } 90 \text { shoulders) }\end{array}$} & \multirow{2}{*}{$\chi^{2} / \mathrm{Z}$} & \multirow{2}{*}{$p$} & \multicolumn{2}{|c|}{$\begin{array}{l}\text { Non inflammatory MSUS } \\
\text { findings ( } 90 \text { shoulders) }\end{array}$} & \multirow{2}{*}{$\chi^{2} / Z$} & \multirow{2}{*}{$p$} \\
\hline & $\begin{array}{l}\text { Presence } \\
43 \text { shoulder }\end{array}$ & $\begin{array}{l}\text { Absence } \\
47 \text { shoulder }\end{array}$ & & & $\begin{array}{l}\text { Presence } \\
65 \text { shoulder }\end{array}$ & $\begin{array}{l}\text { Absence } \\
25 \text { shoulder }\end{array}$ & & \\
\hline Age (yrs) & $46.6 \pm 12.8$ & $39.72 \pm 9.80$ & -2.854 & 0.006 & $44.8 \pm 12.17$ & $38.40 \pm 9.46$ & -2.645 & 0.01 \\
\hline $\begin{array}{c}\text { Sex: } \\
\text { F } \\
\text { M }\end{array}$ & $\begin{array}{l}37(86 \%) \\
6 \quad(14 \%)\end{array}$ & $\begin{array}{l}41(87.2 \%) \\
6 \quad(12.8 \%)\end{array}$ & 0.027 & 0.869 & $\begin{array}{l}57(87.7 \%) \\
8 \quad(12.3 \%)\end{array}$ & $\begin{array}{l}21(84 \%) \\
4 \quad(16 \%)\end{array}$ & 0.213 & 0.732 \\
\hline Dis. dur. (ys) & $5 \quad(1-10)$ & $3(2-10)$ & $-0.707-$ & 0.480 & $5 \quad(1-9)$ & $3 \quad(2-10)$ & -0.082 & 0.935 \\
\hline Pain dur. (month) & $3 \quad(1-12)$ & $5(1-12)$ & -0.163 & 0.871 & $4 \quad(1-11)$ & $3 \quad(1-12)$ & -.372 & 0.710 \\
\hline BMI & $27.48 \pm 4.47$ & $28.29 \pm 5.50$ & 0.947 & 0.346 & $27.92 \pm 4.68$ & $28.22 \pm 5.95$ & 0.253 & 0.801 \\
\hline DAS 28 ESR & $5.43 \pm 1.04$ & $5.08 \pm 1.2$ & -1.473 & 0.144 & $5.27 \pm 1.13$ & $5.17 \pm 1.19$ & -.373 & 0.710 \\
\hline VAS (0-100) & $70(60-70)$ & $60(50-80)$ & -0.946 & 0.344 & $70(60-75)$ & $60(50-80)$ & -1.463 & 0.144 \\
\hline $\operatorname{ESR}(\mathrm{mm} / \mathrm{hr})$ & $35(25-50)$ & $26(21-36)$ & -2.501 & 0.012 & $30(21-46)$ & $30(23-40)$ & -.108 & 0.914 \\
\hline $\mathrm{CRP}(\mathrm{mg} / \mathrm{dl})$ & $7 \quad(4-22)$ & $10(4-21)$ & -0.502 & 0.616 & $7 \quad(4-21)$ & $10(4-20)$ & -.713 & 0.476 \\
\hline Anti-CCP (IU/mL) & $66(37-200)$ & $89(46-160)$ & -0.186 & 0.853 & $89(37-185)$ & $99(46-141)$ & -.252 & 0.801 \\
\hline $\mathrm{RF}(\mathrm{IU} / \mathrm{mL})$ & $22(12-64)$ & $32(14-83)$ & -.800 & 0.423 & $32(13-82)$ & $28(13-79)$ & -.117 & 0.907 \\
\hline
\end{tabular}

BMI : Body Mass Index.

Dis. dur : Disease duration.

VAS : Visual Analogue Scale. $\begin{array}{ll}\text { ESR } & \text { : Erythrocyte Sedimentation Rate. } \\ \text { CRP } & \text { : C-Reactive Protein. }\end{array}$

Anti-CCP (tit) : Anti-cyclic citrullinated antibody titre.

$\mathrm{RF}$ : Rheumatoid Factor.

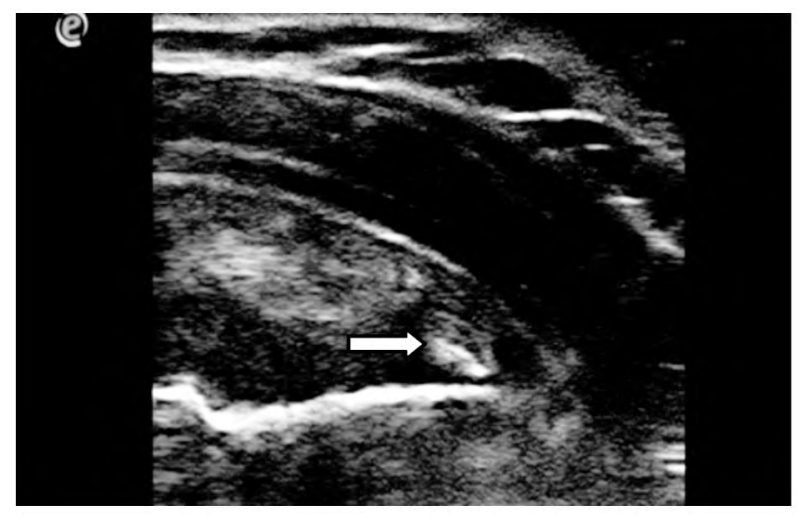

Supra-sp T calcification



Active SASD-B inflammation

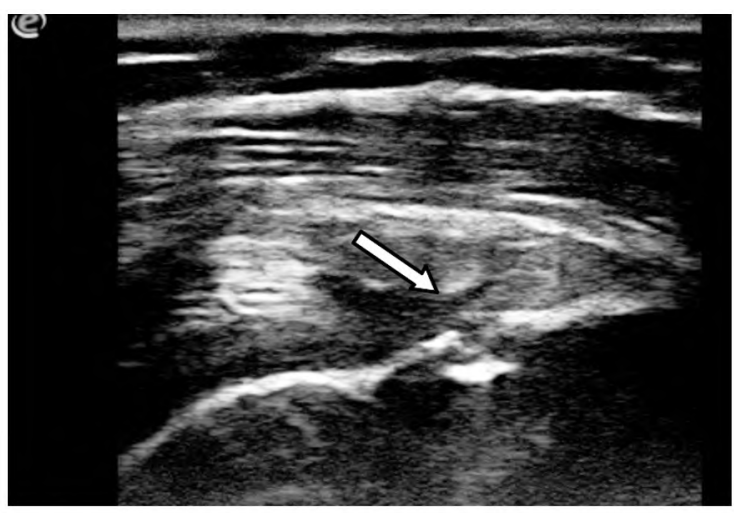

Greater trochanter erosion

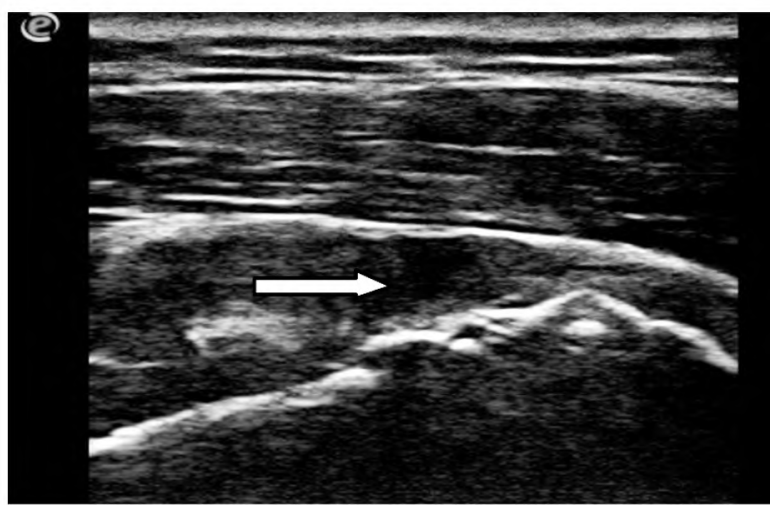

Supra-sp T tear-F

Fig. (1): MSUS images of shoulder abnormalities in Rheumatoid Arthritis patients.

Supra-sp T calcification : Supraspinatus tendon calcification

Active SASD-B inflammation : Active (acute) subacromial subdeltoid bursa inflammation.

Supra-sp T tear-F : Supraspinatus tendon full thickness tear. 


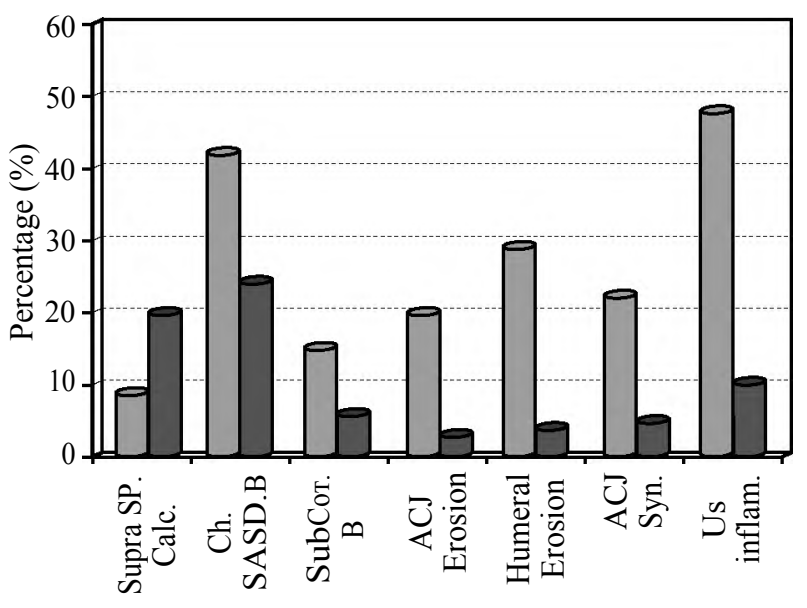

US finding

$$
\text { Case Control }
$$

Fig. (2): Comparison between RA patients and controls as regards some US-detected shoulder lesions.

Supra sp. Calc. : Supraspinatus tendon calcification.

Ch. SASD B. : Chronic subacromial subdeltoid bursa inflammation. Sub cor. B : Subcoracoid bursitis.

ACJ : Acromioclavicular Joint.

US inflam. : Ultrasound inflammatory findings.

On studying the relation between US abnormalities and shoulder pain in RA patients, there was no statistical significant association between shoulder pain and individual MSUS findings except ACJ irregularities and GH effusion. However, there was statistical significant association between shoulder pain and all inflammatory lesions combined, all non-inflammatory lesions combined and all erosions, $p<0.05$ (Table 4).

Table (4): Relation between US abnormalities and shoulder pain in RA patients (45).

\begin{tabular}{|c|c|c|c|c|}
\hline \multirow{2}{*}{$\begin{array}{l}\text { MSUS abnormalities } \\
\text { ( } 90 \text { shoulders) }\end{array}$} & \multicolumn{2}{|c|}{ Shoulder pain } & \multirow{2}{*}{$x^{2}$} & \multirow[b]{2}{*}{$p$} \\
\hline & $\begin{array}{c}\text { Presense } \\
(+\mathrm{ve})\end{array}$ & $\begin{array}{c}\text { Presense } \\
(-\mathrm{ve})\end{array}$ & & \\
\hline \multicolumn{5}{|l|}{ GH effusion: } \\
\hline$\overline{+}$ & $\begin{array}{l}20(36.4 \%) \\
35(36.6 \%)\end{array}$ & $\begin{array}{lr}6 & (17.1 \%) \\
29 & (82.9 \%)\end{array}$ & 3.846 & 0.05 \\
\hline \multicolumn{5}{|l|}{ ACJ irregularities: } \\
\hline$\overline{+}$ & $\begin{array}{l}22(37.3 \%) \\
37(62.7 \%)\end{array}$ & $\begin{array}{ll}4 & (12.9 \%) \\
27 & (87.1 \%)\end{array}$ & 5.882 & 0.015 \\
\hline \multicolumn{5}{|l|}{ All inflammatory: } \\
\hline$\overline{+}$ & $\begin{array}{l}20(42.6 \%) \\
27(57.4 \%)\end{array}$ & $\begin{array}{ll}6 & (14 \%) \\
37(86 \%)\end{array}$ & 8.941 & 0.003 \\
\hline \multicolumn{5}{|c|}{ All non-inflammatory: } \\
\hline$\overline{+}$ & $\begin{array}{l}11(44 \%) \\
14(56 \%)\end{array}$ & $\begin{array}{l}15(23.1 \%) \\
50(76.9 \%)\end{array}$ & 3.848 & 0.05 \\
\hline $\begin{array}{l}\text { All erosions: } \\
\qquad \overline{+}\end{array}$ & $\begin{array}{l}20(36.4 \%) \\
35(63.6 \%)\end{array}$ & $\begin{array}{lr}6 & (17.1 \%) \\
29 & (82.9 \%)\end{array}$ & 3.846 & 0.05 \\
\hline
\end{tabular}

Comparison between RA patients with unilateral versus bilateral shoulder MSUS abnormalities in gender, age, BMI, DAS-28 score, disease duration, pain duration, VAS, ESR, CRP, RF titre, anti-CCP antibodies titre revealed no statistical significant difference $\left(\mathrm{X}^{2}=0.355, t=0.287,1.313\right.$ and $0.716, \mathrm{z}$ $=0.638,0.200,0.055,1.630,0.165,1.310$, and 0.344 respectively), $p=0.837,0.775,0.196,0.478$, $0.524,0.842,0.957,0.103,0.244,0.190,0.731$, respectively (data not shown).

Regarding X-ray shoulder findings, osteoporosis, joint space narrowing, osteophytes, erosions, calcifications were detected in $5(5.6 \%), 12$ (13.3\%), 7 (7.8\%), $6(6.7 \%)$, zero\% of RA patients respectively versus zero \%, 4 (4.4\%), 4 (4.4\%), zero $\%, 2(2.2 \%)$ in controls with only significant statistical difference as regards joint space narrowing and erosions, $p=0.032$ and $p=0.029$ respectively (data not shown).

On studying agreement between MSUS and Xray in detecting osteophytes, erosions and calcifications in 180 shoulders (RA patients and controls) using Kappa agreement measure, MSUS detected erosions in $42 / 180$ versus $6 / 180$ by X-ray, of the 42 MSUS detected erosions X-ray detected only $4(9.5 \%)$, on the other hand of the 138 MSUS -ve erosions, X-ray agreed in $136(98.6 \%)$, kappa= $0.115, p=0.01$. MSUS detected osteophytes in $73 / 180$ shoulders versus $11 / 180$ by X-ray with +ve agreement in $6(8.2 \%)$ and -ve agreement in 102 (95.3\%), kappa $=0.04, p=0.329$. Calcifications detected by MSUS in 27/180 shoulders versus 2/180 by X-ray.

\section{Discussion}

The early and definitive diagnosis of a chronic inflammatory joint disease is crucial for initiating optimal treatment [18].

The current study included 45 RA patients and 45 age and sex matched patients serving as controls both had unilateral or bilateral shoulder pain. Our study participants were homogenous with no statistical significant difference between RA patients and controls regarding age, sex, BMI or shoulder pain duration, $p>0.05$.

In our study MSUS abnormalities were detected in $43 / 45(95.5 \%)$ in RA patients, unilateral in 13 $(28.9 \%)$ and bilateral in $30(66.7 \%)$ versus $41 / 45$ $(91.1 \%)$ of controls, unilateral in $16(35.6 \%)$ and bilateral in $25(55.6 \%)$ with no statistical significant difference $p>0.05$. Shoulder pain was reported in 64 (71\%) RA shoulders Vs. $51(56.7 \%)$ in controls and pain was bilateral in $19(42 \%)$ in RA shoulders 
Vs. $6(13.3 \%)$ in controls with statistical significant difference $p<0.05$. The commonest MSUS shoulder abnormality in our RA patients versus controls was SASD bursitis in $38(42.2 \%)$ versus $21(23.3 \%)$ followed by GH effusion 35 (38.9\%) Vs. 24 (26.7\%), supraspinatus TP $32(35.6 \%)$ Vs. 32 (35.6\%), ACJ osteophytes 32 (35.6\%) Vs. 38 (42.2\%), humeral head erosions $26(28.9 \%)$ Vs. 4 (4.4\%), ACJ synovitis $20(22.2 \%)$ Vs. 5 (5.6\%) in controls. There was statistical significant difference between RA patients and controls as regards frequency of supraspinatus calcification, ch.SASD $\mathrm{B}$, subcoracoid B, ACJ erosion, ACJ synovitis, humeral head erosion, $p<0.05$.

The frequency of abnormal MSUS findings of rheumatoid shoulder joints differs depending on the patient population studied. In a study evaluating 44 hospitalized RA patients with mean disease duration of 12 years, subacromial bursitis was the most frequent finding that agreed with our results, followed by GH joint synovitis [19]. In another MSUS study evaluating 100 patients with RA with mean disease duration of 4.5 years, 14 cases presented with involvement of the GHJ and 22 with inflammatory abnormalities of the SAD bursa [20] In Elbinoune et al., study [21] MSUS abnormalities were found in $83.8 \%$ of RA patients; bilateral in $59.5 \%$ of them. The most frequent MSUS findings were erosion $(64.9 \%)$ followed by effusion $(54.1 \%)$ and synovial hypertrophy (43.2\%) in GHJ, SAD bursitis $(37.8 \%)$ and Doppler signal in GHJ (10.8\%). Fuda et al., study [22] detected that 21 $(52.5 \%)$ of RA patients had erosions, $18(45 \%)$ had synovitis, 21 (52.5\%) had Long Head Of Biceps (LHB) tenosynovitis, 7 (17.5\%) bursitis, and 18 (45\%) supraspinatus tendinopathy by MSUS on shoulders. Kim et al., [2], found that the most frequent finding was effusion in the long head of the biceps tendon, which was observed in $37.1 \%$ of painful shoulders. It was also observed in $36 \%$ of non-painful shoulders. Biceps tendon rupture and subdeltoid effusion were detected in $14.3 \%$ of painful shoulders, respectively. Among the rotator cuff tendons, subscapularis was the most frequently involved, followed by supraspinatus and infraspinatus tendon.

In our study, inflammatory MSUS shoulder abnormalities (TS, S, active bursitis, erosions) were reported in $43(47.8 \%)$ of RA patients Vs. 18 (20.0\%) in controls with statistical significant difference $p<0.05$. On the other hand despite more frequent non inflammatory (degenerative) MSUS findings (TP, tears, ch. bursitis, osteophytes) in RA patients Vs. controls (65 (72.2\%) Vs. 60 $(66.7 \%))$ no statistical significant difference was present $p>0.05$. Strunk et al., showed that power Doppler sonography helps to differentiate between degenerative shoulder disorders and rheumatoid shoulder [23] . Elbinoune et al., [21] assessed the sites of inflammation in painful rheumatoid shoulder by ultrasound and power Doppler, the most common MSUS finding was effusion or synovitis in $59 \%$ of painful GHJ accompanied or not with subdeltoid bursitis, detectable in the posterior scan in $87 \%$ of shoulders. MSUS joint erosions on the humeral head were detected in 59\% of joints with longer disease duration [24]. This is partially consistent with our results. In Fuda et al., study [22] shoulders US inflammatory findings were as follows: 21 (52.5\%) RA patients studied had erosions, $18(45 \%)$ synovitis, 21 (52.5\%) Long Head of Biceps (LHB) tenosynovitis, seven (17.5\%) bursitis.

On studying the association between the frequency of these inflammatory MSUS shoulder abnormalities with various clinical and laboratory parameters in RA patients, they were significantly related to older ages and higher ESR (reflects disease activity). On the other hand degenerative MSUS shoulder abnormalities were significantly related to older ages. These results almost agreed with those of Elbinoune et al., [21], where in particular, synovial hypertrophy was associated with advanced age, and signal Doppler with advanced age, shorter disease duration and with higher disease activity assessed by Simple Disease Activity Index (SDAI). Presence of SAD bursitis was not linked to disease activity as in our study. Against our findings, abnormalities in anterior recess GHJ were associated with elevated synovial index and rheumatoid factor level. In a study done by Sakellariou et al., [25] patients with MSUS inflammatory involvement had longer median disease duration, were more frequently RF positive, had a higher disease activity and higher acute phase reactants, a higher level of disability and more pain. However, Fuda et al., [22], reported absence of relation between each of shoulder erosion, TS or bursitis with ESR or DAS 28 score. While, there were significant relation between supraspinatus TP, ESR and DAS28. Bursitis was related to CRP.

Absence of RA patients in remission or with mild disease activity in our study in addition to small sample size may account for lack of strong relation between MSUS inflammatory findings and other parameter of disease activity except ESR. Also, SDAI as an index of RA activity was been shown superior over DAS-28 by Balsa et al., [26] Some other studies included joint effusion and supraspinatus tendinopathy as inflammatory findings. Also, we studied the relation between MSUS 
detected inflammatory (total No. and \%) shoulder abnormalities and different clinical and laboratory disease characteristics including that of disease activity, while other studies evaluated the relation of each MSUS finding to these characteristics. In addition, different equipment or MSUS protocols may account for different results.

On studying the relation between MSUS abnormalities and shoulder pain in RA patients, there was no statistical significant association between shoulder pain and individual MSUS findings except ACJ irregularities and GH effusion $p<0.05$. However, there was statistical significant association between shoulder pain and all (combined) inflammatory lesions, all (combined) non inflammatory lesions and all erosions, $p<0.05$, which confirmed the limitation of small sample size in our work.

The study done by Fuda et al., [22], reported significant relation between supraspinatus tendinopathy and shoulder TS but not shoulder erosions, bursitis or synovitis with shoulder pain. Gill et al. [27], detected that MRI shoulder pathology was apparent in both symptomatic and asymptomatic shoulders and clinical symptoms may not match radiological findings. Sakellariou et al., found that patients with MSUS inflammatory involvement had increased frequency of spontaneous shoulder pain and higher median VAS pain [25]

In our study X-ray detected statistically significant more joint space narrowing and erosions in RA patients compared to controls, $p=0.032$ and 0.029 respectively. On studying agreement between MSUS and X-ray in detecting osteophytes, erosions and calcifications in 180 shoulders (patients and controls) using Kappa agreement measure, MSUS detected erosions in 42/180 (23.3\%) Vs. $6 / 180$ (3.3\%) by X-ray with + agreement only in $4(9.5 \%)$ and -ve agreement in 136 (98.6\%), kappa $=0.115$, $p=0.01$. MSUS detected osteophytes in $73 / 180$ $(40.5 \%)$ shoulders versus $11 / 180(6.1 \%)$ and calcifications in $27 / 180(15.0 \%)$ shoulders versus $2 / 180(1.11 \%)$ by X-ray with non-significant agreement. These findings indicate general superiority of MSUS over X-ray in better detection of erosions, osteophytes, and calcifications. The data published in the literature show ultrasound to have a higher sensitivity than radiography [28-30]. Wakefield et al. [31], documented that MSUS is a reliable technique that detects more erosions compared with conventional radiography, especially in early RA. A study by Babini et al., [32] that investigated the shoulder by conventional radiography demonstrated erosions in the superolateral area of the glenohumeral joint in $20 \%$ of 56 patients with RA. Fuda et al., [22], demonstrated erosion in the shoulder using MSUS in $21(52.5 \%)$ cases and using conventional radiography in $18(45 \%)$ cases; and concluded that MSUS was more diagnostic for erosion in RA. Hermman et al., [18], identified erosions in $60 \%$ of RA patients. Their results show that the detection rate of ultrasound is higher than that of conventional radiography, but the difference was not statistically significant.

In Conclusion MSUS detected shoulder inflammatory abnormalities are more frequent, symptomatic, and usually bilateral in RA patients. They are related to shoulder pain (which is more frequent and bilateral compared to controls), old age and disease activity. Early diagnosis of a chronic inflammatory joint disease by US, proved superiority to conventional radiography, is crucial for initiating optimal treatment.

\section{References}

1- MERONI R., PISCITELLI D., VALERIO S., et al.: Ultrasonography of the shoulder: Asymptomatic findings from working-age women in the general population. J. Phys. Ther. Sci., 29: 1219-23, 2017.

2- KIM H.A., KIM S.H. and SEO YOUNG-I.L.: Ultrasonographic Findings of the Shoulder in Patients with Rheumatoid Arthritis and Comparison with Physical Examination. J. Korean Med. Sci., 22: 660-6, 2007.

3- KUPER H.H., VAN LEEUWEN M.A., VAN RIEL P.L., et al.: Radiographic damage in large joints in early rheumatoid arthritis: Relationship with radiographic damage in hands and feet, disease activity and physical disability. Br. J. Rheumatol., 36 (8): 855-60, 1997.

4- DROSSERS-BAKKER K.W., KROON H.M., ZWINDERMAN A.H., et al.: Radiographic damage of large joints in long-term rheumatoid arthritis and its relation to function. Rheumatology (Oxford), 39 (9): 998-1003, 2000.

5- NAREDO E., AGUADO P., De MIGUEL E., et al.: Painful shoulder: Comparison of physical examination and ultrasonographic findings. Ann. Rheum. Dis., 61 (2): 132-6, 2002.

6- SMOLEN J.S., ALETAHA D., BIJLSMA J.W., et al.: Treating rheumatoid arthritis to target: Recommendations of an international task force. Ann. Rheum. Dis., 69 (4): 631-7, 2010.

7- BACKHAUS M., KAMRADT T. , SANDROCK D., et al.: Arthritis of the finger joints: A comprehensive approach comparing conventional radiography, scintigraphy, ultrasound, and contrast-enhanced magnetic resonance imaging. Arthritis Rheum., 42: 1232-45, 1999.

8- KLARLUND M., OSTERGAARD M., GIDEON P., et al.: Wrist and finger joint MR imaging in rheumatoid arthritis. Acta Radiol., 40: 400-9, 1999.

9- KLARLUND M., OSTERGAARD M., ROSTRUP E., et al.: Dynamic magnetic resonance imaging of the metacarpophalangeal joints in rheumatoid arthritis, early unclassified polyarthritis, and healthy controls. Scand J. Rheumatol., 29: 108-15, 2000. 
10- WAKEFIELD R.J., GIBBON W.W., CONAGHAN P.G., et al.: The value of sonography in the detection of bone erosions in patients with rheumatoid arthritis: A comparison with conventional radiography. Arthritis Rheum., 43: 2762-70, 2000 .

11- HERMANN K.G.A., BACKHAUS M., SCHNEIDER U., et al.: Rheumatoid Arthritis of the Shoulder Joint Comparison of Conventional Radiography, Ultrasound, and Dynamic Contrast-Enhanced Magnetic Resonance Imaging. Arthritis Rheum., 48 (12): 3338-49, 2003.

12- ELBINOUNE I., AMINE B., WABI1 M., et al.: Rheumatoid shoulder assessed by ultrasonography: Prevalence of abnormalities and associated factors. Pan. African Medical Journal, 24: 235, 2016.

13-ALETAHA D., NEOGI T., FELSON D., et al.: Rheumatoid Arthritis classification criteria: ACR/EULAR classification criteria for diagnosis of Rheumatoid Arthritis. Arthritis Rheumatism, 62: 2569-81, 2010.

14- PREVOO M.L., VANT HOF M.A., VAN RIEL P.L., et al.: Modified disease activity scores that include twenty eightjoint counts. Development and validation in a prospective longitudinal study of patients with rheumatoid arthritis: Arthritis Rheum., 38: 44-8, 1995.

15- NAREDO E., USON J., ACEBES C., et al.: Joint ultrasonography: Sonoanatomy and examination technique. Barcelona, SL: Euromedice, Ediciones Medicas, 2007.

16- PETRANOVA T., VLAD V., PORTA F., et al.: Ultrasound of the shoulder. Med. Ultrason., 14: 133-40, 2012.

17- BEGGS I.: Shoulder ultrasound. Semin Ultrasound CT MR, 32: 101-13, 2011.

18- HERMANN K.A., BACKHAUS M., SCHNEIDER U., et al.: Rheumatoid Arthritis of the Shoulder Joint. Comparison of Conventional Radiography, Ultrasound, and Dynamic Contrast-Enhanced Magnetic Resonance Imaging Arthritis Rheum., 48 (12): 3338-49, 2003.

19- ALASAARELA E.M. and ALASAARELA E.L.: Ultrasound evaluation of painful rheumatoid shoulders. J. Rheumatol., 21 (9): 642-8, 1994.

20- SAKELLARIOU G., IAGNOCCO A., FILIPPUCCI E., et al.: Ultrasound imaging for the rheumatologist XLVIII Ultrasound of the shoulders of patients with rheumatoid arthritis. Clin. Exp. Rheumatol., 31 (6): 837-42, 2013.

21- ELBINOUNE I., AMINE B., WABI M., et al.: Rheumatoid shoulder assessed by ultrasonography: Prevalence of abnormalities and associated factors. Pan. African Medical Journal, 24: 235, 2016.
22- FUDA A.I., HASHAAD N.I., GALAL O., et al.: Ultrasonographic findings of the shoulders in Egyptian patients with rheumatoid arthritis. Egyptian Rheumatology \& Rehabilitation, 44: 17-23, 2017.

23- STRUNK J., LANGE U., KURTEN B., et al.: Doppler sonographic findings in the long bicipital tendon sheath in patients with rheumatoid arthritis as compared with patients with degenerative diseases of the shoulder. $\mathrm{Ar}$ thritis Rheum., 48 (7): 1828-32, 2003.

24- STEGBAUER J., RUMP L.C. and WEINER S.M.: Sites of inflammation in painful rheumatoid shoulder assessed by musculoskeletal ultrasound and power Doppler sonography. Rheumatol. Int., 28 (5): 459-65, 2008.

25- SAKELLARIOU G., IAGNOCCO A., FILIPPUCCI E., et al.: Ultrasound imaging for the rheumatologist XLVIII Ultrasound of the shoulders of patients with rheumatoid arthritis. Clin. Exp. Rheumatol., 31 (6): 837-42, 2013.

26- BALSA A., MIGUELL E., et al.: Superiority of SDAI over DAS28 in assessment of remission in rheumatoid arthritis patients using power Doppler ultrasonography as a gold standard. Rheumatology, 49 (4): 683-90, 2010.

27- GILL T.K., SHANAHAN E.M., ALLISON D., et al.: Prevalence of abnormalities on shoulder MRI in symptomatic and asymptomatic older adults. Int. J. Rheum. Dis., 17 (8): 863-71, 2014.

28- JANTSCH S., ZENZ P. and SCHWAGERL W.: Radiologic and sonographic screening study of shoulder joints of patients with rheumatoid arthritis. Z Gesamte Inn. Med., 46: 512-7, 1991.

29- ALASAARELA E., SURAMO I., TERVONEN O., et al.: Evaluation of humeral head erosions in rheumatoid arthritis: A comparison of ultrasonography, magnetic resonance imaging, computed tomography and plain radiography. Br. J. Rheumatol., 37: 1152-6, 1998.

30- HODLER J., TERRIER B., VON SCHULTHESS G.K., et al.: MRI and sonography of the shoulder. Clin. Radiol., 43: 323-7, 1991.

31- WAKEFIELD R.J., BALINT P.V., SZKUDLAREK M., et al.: The value of sonography in the detection of bone erosions in patients with rheumatoid arthritis: A comparison with MRI. J. Rheumatol., 32: 2485-7, 2005.

32- BABINI J.C., GUSIS S.E., BABINI S.M., et al.: Superolateral erosions of the humeral head in chronic inflammatory arthropathies. Skeletal Radiol., 21: 515-7, 1992. 


\section{التغيرات الغير طبيعية المصحوبة بإلتهاب في مقابل الغير مصحوبة بإلتهاب

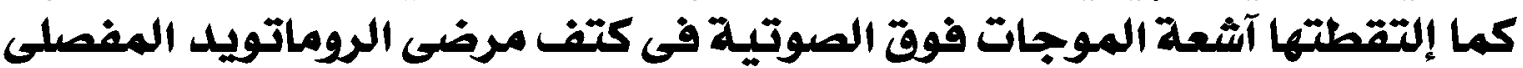 الذين يعانون من آله بالكتف فئف مرفي}

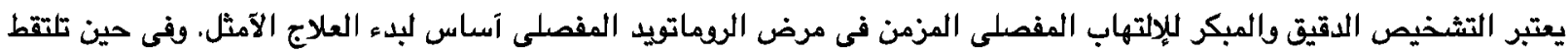

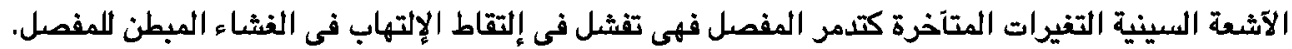

قد كان الهدف من هذه الدراسة هو مقارنة نوع ونسبة التغيرات غير الطبيعية المصحوبة بإلتهاب فى مقابل الغير مصحوبة بإلتهاب كما

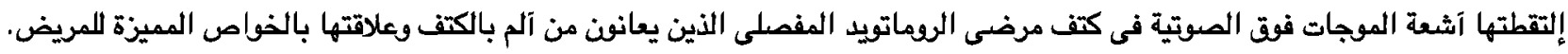
وقد تم فصص آكتاف هع من مرضى الروماتويد المفصلى وهع من المتطوعين المصابين بآلم الكتف كمجموعة ضابطة بواسطة آشعة آشعائ



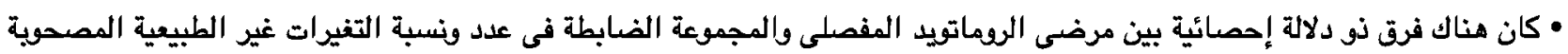

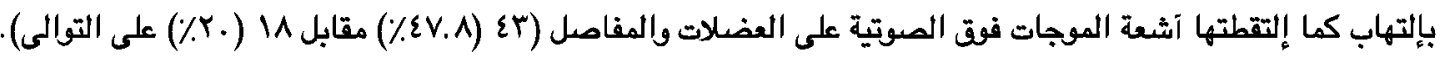

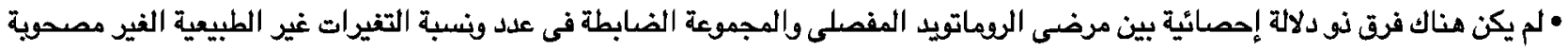

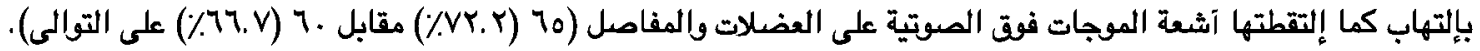

• فى مرضى الروماتويد المفصلى، كان هناك علاقة ذات دلالة إحصائية بين وجود التغيرات غير الطبيعية المصحوبة بإلتهاب كما إلتقطتها آشعة الثعائ

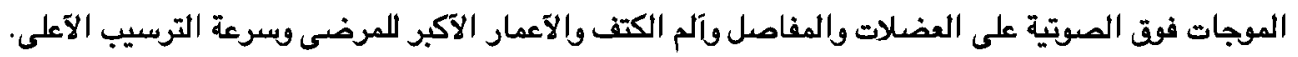

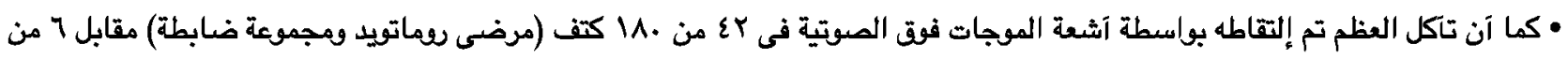

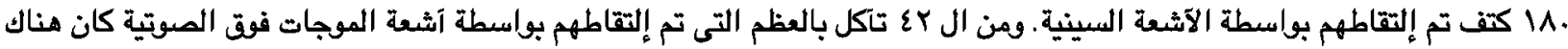

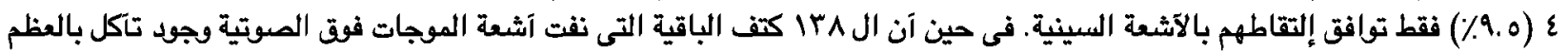

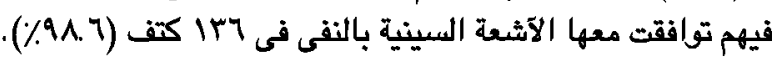

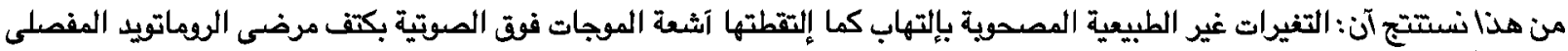



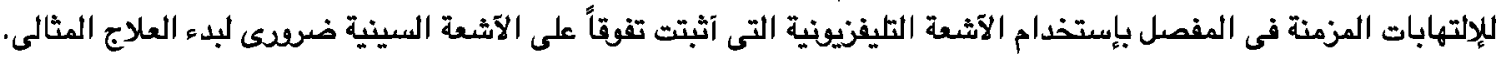

